\title{
Multiband Printed Asymmetric Dipole Antenna for LTE/WLAN Applications
}

\author{
Chia-Mei Peng, ${ }^{1,2}$ I-Fong Chen,, ${ }^{1,2}$ and Chin-Hao Liu ${ }^{3}$ \\ ${ }^{1}$ Department of Electronic Engineering, Jinwen University of Science and Technology, 23154 No. 99, An-Chung Road, Hsin-Tien, \\ New Taipei City, Taiwan \\ ${ }^{2}$ Wieson Corp. Tech., 221 No. 276, Section 1, Datong Road, Sijihih, New Taipei City, Taiwan \\ ${ }^{3}$ Department of Electronic Engineering, National Taiwan University of Science and Technology, 10608 No. 43, Section 4, Keelung Road, \\ Daian, Taipei, Taiwan \\ Correspondence should be addressed to I-Fong Chen; ex0206@just.edu.tw
}

Received 16 September 2013; Accepted 7 December 2013

Academic Editor: Xiao Ping Chen

Copyright (c) 2013 Chia-Mei Peng et al. This is an open access article distributed under the Creative Commons Attribution License, which permits unrestricted use, distribution, and reproduction in any medium, provided the original work is properly cited.

The ability of a single layer strip fed printed asymmetric dipole antenna, which is composed of top-loading, asymmetric coplanar waveguide (ACPW) and stepped-feeding structure, to operate at three wide frequency bands $(698 \sim 960 \mathrm{MHz}, 1710 \sim 2620 \mathrm{MHz}$, and $5150 \sim 5850 \mathrm{MHz}$ ) to cover WLAN and LTE operation has been demonstrated. A prototype of the proposed antenna with $57.5 \mathrm{~mm}$ in length, $0.4 \mathrm{~mm}$ in thickness, and $5 \mathrm{~mm}$ in width is fabricated and experimentally investigated. The experimental results indicate that the VSWR 2.5:1 bandwidths achieved were $74.3 \%, 40.8 \%$, and $18.2 \%$ at $700 \mathrm{MHz}, 2450 \mathrm{MHz}$, and $5500 \mathrm{MHz}$, respectively. Experimental results are shown to verify the validity of theoretical work.

\section{Introduction}

Recently, the antennas desired features include multiband, broad bandwidth, simple impedance matching to the feed line, and low profile, to be used in various wireless communication applications, such as the IEEE 802.11 wireless local area network (WLAN) standards, and the pre-4G technologies such as long term evolution (LTE) standards. A variety of printed monopole antennas for covering multibands have been reported in the published articles [1-5], those types of printed monopole antenna designs occupy a relatively larger space and they are difficult to meet the size-limitation of the external antenna. In industrial applications involving external antennas with tapered streamline radome covers, the space limitations are an important issue. In this paper, we present a single layer multiband printed asymmetric dipole antenna for LTE/WLAN external antenna applications. The arm-lengths of dipole are designed to response two different resonant frequencies, respectively. It is beneficial to enhance antenna performance by letting the length of the groundarm of dipole antenna be larger than the signal-arm [6]. In other words, the signal-arm of dipole antenna is designed for upper-operating band, and the ground-arm is designed for lower-operating band. The proposed antenna is consisted of top loading, asymmetric coplanar waveguide (ACPW) and stepped-feeding structure, which was developed by modifying the structure of printed sleeve monopole antenna [7]. The feasibility of wide bandwidth operation has been proven by the design of ACPW feeding structure and groundtrace structure that operates in the WLAN and LTE bands. Details of the design considerations of the proposed antenna and the experimental results of constructed prototypes are presented and discussed.

\section{Antenna Structure and Design}

As for the specification requirement of wireless products, the multiband antenna is required to enable operations at the two WLAN and the LTE bands, whose bandwidths and list of the corresponding bands are detailed in Table 1 . The operating frequency rangeis divided into three bands: $700 \mathrm{MHz}$ 
TABLE 1: Considered WLAN and LTE bands.

\begin{tabular}{|c|c|}
\hline Allocated bands & Frequency range $(\mathrm{MHz})$ \\
\hline \multicolumn{2}{|c|}{ LTE } \\
\hline \multicolumn{2}{|l|}{ FDD } \\
\hline$\# 5, \# 6, \# 8, \# 12, \# 13, \# 14, \# 17, \# 18, \# 19, \# 20$ & $698-960$ \\
\hline$\# 1, \# 2, \# 3, \# 4, \# 9, \# 10$ & $1900-2620$ \\
\hline \multicolumn{2}{|l|}{ TDD } \\
\hline \multirow[t]{2}{*}{$\# 33, \# 34, \# 35, \# 36, \# 37, \# 38, \# 39, \# 40, \# 41$} & $1850-2690$ \\
\hline & \\
\hline $2.4 \mathrm{GHz}$ & $2400-2500$ \\
\hline $5 \mathrm{GHz}$ & $5150-5850$ \\
\hline
\end{tabular}

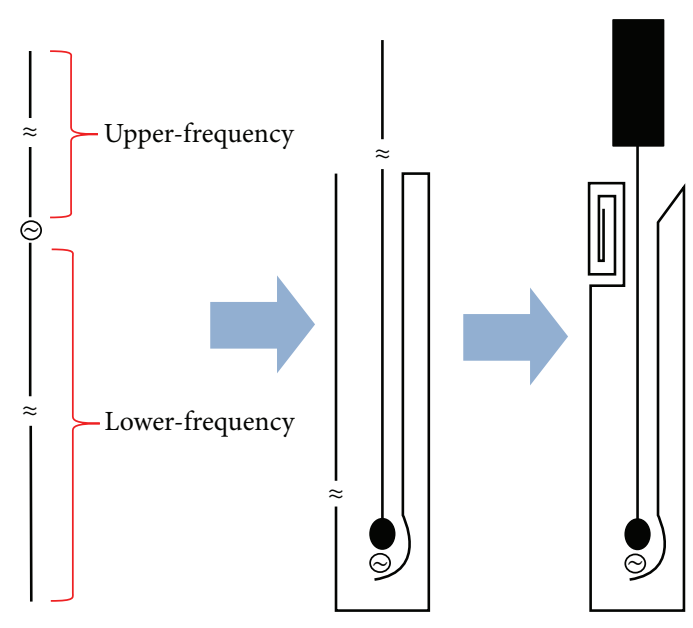

(a)
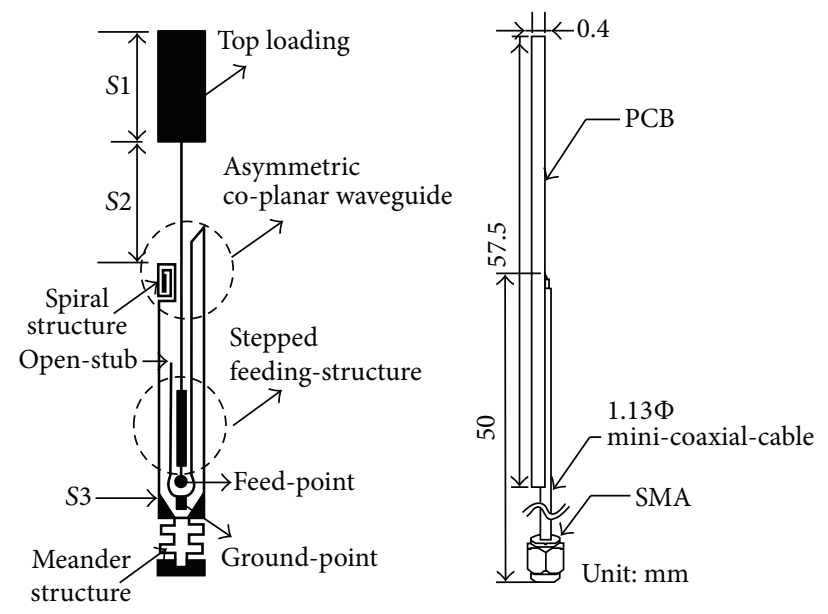

(b)

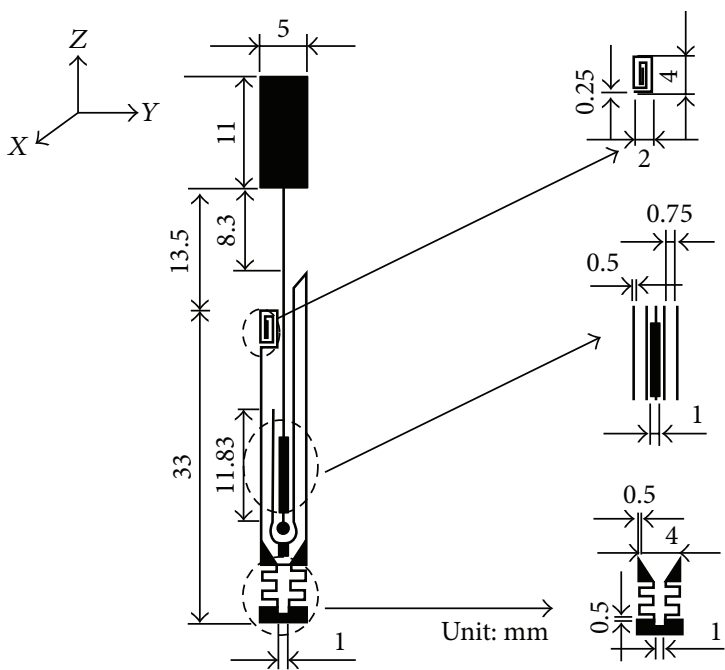

(c)

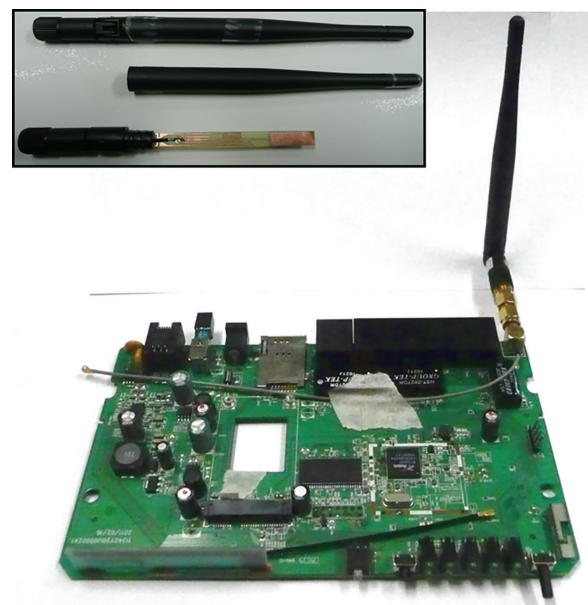

(d)

FIGURE 1: (a) The original geometry structure of the proposed antenna. (b) Profile and side view of the proposed antenna. (c) Configuration and dimensions of the proposed antenna. (d) The tapered streamline radome cover of antenna.

band $(698 \mathrm{MHz}-960 \mathrm{MHz}), 2450 \mathrm{MHz}$ band $(1710 \mathrm{MHz}-$ $2620 \mathrm{MHz}$ ), and $5500 \mathrm{MHz}$ band $(5150 \mathrm{MHz}-5850 \mathrm{MHz})$; in which the $700 \mathrm{MHz}$ band was denoted as lower-operating band, and $2450 \mathrm{MHz}$ and $550 \mathrm{MHz}$ bands were denoted as upper-operating band.
Accordingly, a good impedance matching in those operating ranges is needed. Such a requirement has been conveniently expressed in terms of VSWR by imposing a suitable threshold on the magnitude values of the VSWR $\leq 2.5$. Figure 1(a) shows the original geometry asymmetric dipole 
TABLE 2: Measured results of the antenna bandwidth as a function of varying antenna structure.

\begin{tabular}{|c|c|c|c|}
\hline Antenna structure & $\begin{array}{c}\text { Lower band } \\
\text { Bandwidth, } f_{L} \sim f_{U}(\mathrm{MHz})\end{array}$ & $\begin{array}{c}\text { Upper band (I) } \\
\text { Bandwidth, } f_{L} \sim f_{U}(\mathrm{MHz})\end{array}$ & $\begin{array}{c}\text { Upper band (II) } \\
\text { Bandwidth, } f_{L} \sim f_{U}(\mathrm{MHz})\end{array}$ \\
\hline Case I & $300,950 \sim 1250$ & $650,2000 \sim 2650$ & $400,5100 \sim 5500$ \\
\hline Case II & $250,880 \sim 1130$ & $1000,2000 \sim 3000$ & $600,4900 \sim 5500$ \\
\hline Case III & $300,700 \sim 1000$ & $600,2000 \sim 2600$ & $800,4500 \sim 5300$ \\
\hline Proposed antenna & $520,680 \sim 1200$ & $1000,1700 \sim 2700$ & $1000,4700 \sim 5700$ \\
\hline
\end{tabular}

TABLE 3: The measured antenna gains and efficiencies within the operating bandwidth of the proposed antenna.

\begin{tabular}{|c|c|c|c|c|}
\hline \multirow{3}{*}{ Frequency } & & Gain (dBi) & & \multirow{3}{*}{ Efficiency (\%) } \\
\hline & $x y$-plane & $y z$-plane & $z x$-plane & \\
\hline & Max. gain & Max. gain & Max. gain & \\
\hline $700 \mathrm{MHz}$ & 0.08 & 1.62 & 1.77 & 58.57 \\
\hline $960 \mathrm{MHz}$ & 0.81 & 1.41 & 1.81 & 63.47 \\
\hline $1710 \mathrm{MHz}$ & 0.65 & 0.57 & 0.8 & 54.91 \\
\hline $2170 \mathrm{MHz}$ & 0.44 & 0.83 & 0.71 & 55.6 \\
\hline $2450 \mathrm{MHz}$ & 0.98 & 1.09 & 1.17 & 62.3 \\
\hline $2700 \mathrm{MHz}$ & 1.18 & 1.44 & 1.21 & 60.7 \\
\hline $5150 \mathrm{MHz}$ & 1.01 & 1.22 & 1.31 & 62.1 \\
\hline $5500 \mathrm{MHz}$ & 0.54 & 0.88 & 1.15 & 56.8 \\
\hline $5850 \mathrm{MHz}$ & 0.35 & 0.48 & 0.77 & 51.6 \\
\hline
\end{tabular}

"Max.: maximum."

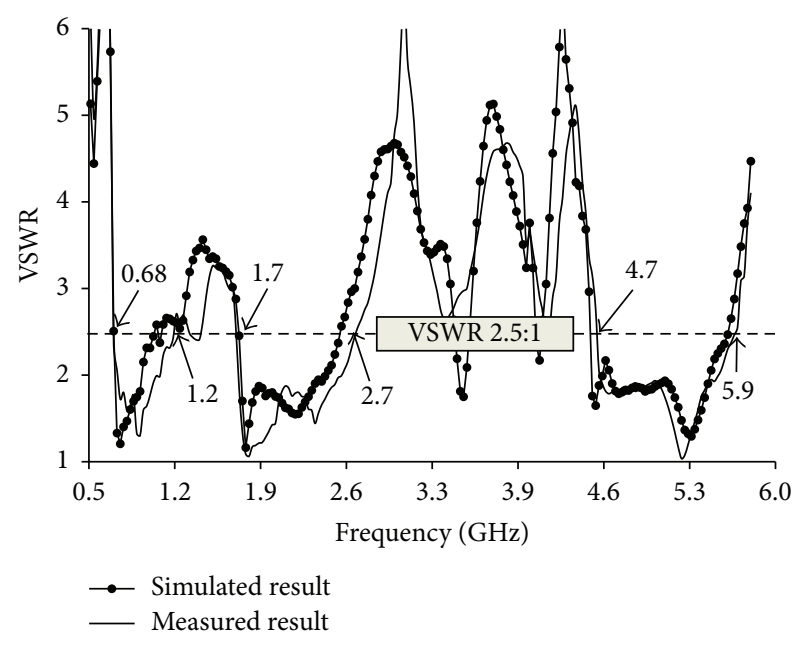

FIGURE 2: Measured and Simulated VSWR against frequency.

antenna for multiband applications. The lengths of signal arm and ground-arm are related to the upper- and lowerfrequency, respectively. The presented antenna structure is composed of an upper-element section of length $S 1$, and the lower-element section of length $S 2$, and the ground-trace section of electrical length $S 3$. These sections are all printed on a $1.6 \mathrm{~mm}$-thick FR4 glass epoxy substrate (the relative permittivity is 4.3 , and the loss tangent is 0.022 ) at the same layer and the profile and side view of the proposed antenna are shown in Figure 1(b). The resonant mode of total shape $(S 1+S 2)$ is designed to occur at $2450 \mathrm{MHz}$, the lower-element

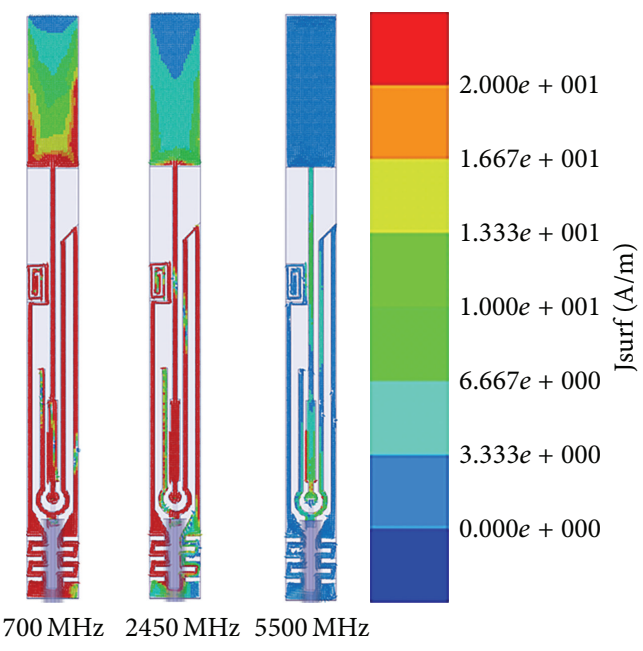

FIgURE 3: The simulated current distribution of the proposed antenna at $700 \mathrm{MHz}, 2450 \mathrm{MHz}$, and $5500 \mathrm{MHz}$.

(S2) is designed to resonate at $5500 \mathrm{MHz}$, and the groundtrace (S3) is designed to resonate at $700 \mathrm{MHz}$. The length of radiating elements can be determined from about quarterwave length at the resonant frequencies. Note that the widths of these sections are not identical. By selecting appropriate dimensions $(S 1, S 2, S 3)$ of the antenna structure, good impedance matching of the printed asymmetric dipole can be obtained across an extended bandwidth. The corresponding characteristics of resonant frequency, input impedance and bandwidth are a function of the geometrical parameters of 


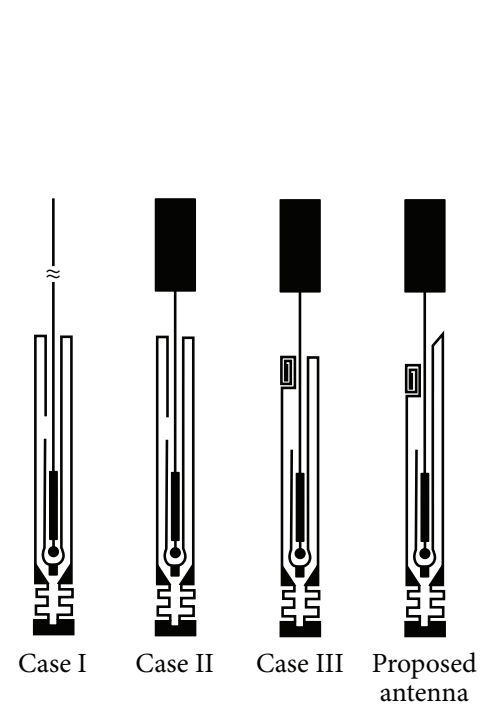

(a)

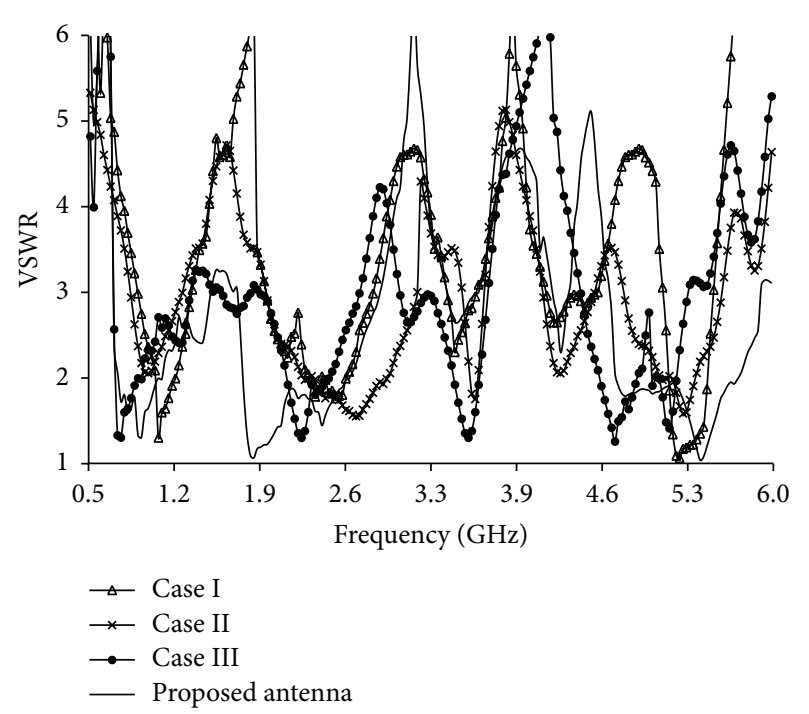

(b)

FIGURE 4: (a) The configuration of varying antenna structure. (b) Measured VSWR against frequency of the corresponding antenna structure.

the top-loading and ACPW structure, the configuration and dimensions of the proposed antenna are shown in Figure 1(c).

When the dimension of the top-loading is varied, the impedance bandwidth and resonant frequency will change in the $2450 \mathrm{MHz}$ band. An ACPW feeding structure excites the end of $S 2$-segment as shown in Figure 1(b). The impedance matching at $2450 \mathrm{MHz}$ and $5500 \mathrm{MHz}$ bands can be tuned by this structure, which was found to be effective in obtaining a wider impedance bandwidth in the antenna's upperoperating band. In addition, it should be noted that the ground-trace length (S3) and configuration could also affect the resonant frequency and operating bandwidth of $700 \mathrm{MHz}$ band; when the printed ground-trace was curled a meanderstructure and spiral-structure, the operating bandwidth will increase. The bended ground-trace is designed for the loweroperating band, which is also act as a sleeve balun for the upper-operating band, a complete radiation pattern-shape can be obtained. The bandwidth enhancement results are demonstrated in the following section. Furthermore, the impedance matching at $700 \mathrm{MHz}, 2450 \mathrm{MHz}$, and $5500 \mathrm{MHz}$ bands can be tuned by the stepped-feeding of signal-trace and the open-stub of the ground-trace, which was found to be effective in securing triple band. The access point (AP) is the intended platform of antenna integration. The proposed antenna's size is based on the size of tapered streamline radome cover, as shown in Figure 1(d).

\section{Experimental Results and Discussion}

In the experiment, the feeding-point and ground-point are connected to a $1.13 \varnothing 3 \mathrm{~cm}$ mini-coaxial cable with $50 \Omega$ SMA connector. By utilizing the above-mentioned design procedure, a wide band antenna was constructed to operate at the ranges of WLAN and LTE system $(698 \sim 960 \mathrm{MHz}$,
$1710 \sim 2690 \mathrm{MHz}$ and $5150 \sim 5850 \mathrm{MHz}$ ). Figure 2 shows the simulated (by Ansoft HFSS) and measured VSWR plot of the wideband antenna as a result of this geometry. The measured VSWR $\leq 2.5$ bandwidths are $74.3 \%$ at $700 \mathrm{MHz}$, $40.8 \%$ at $2450 \mathrm{MHz}$ and $18.2 \%$ at $5500 \mathrm{MHz}$. There is good agreement between the measured and simulated results. Figure 3 presents the simulated current distribution of the proposed antenna at $700 \mathrm{MHz}, 2450 \mathrm{MHz}$, and $5500 \mathrm{MHz}$ which are corresponding to the resonant lengths of the $S 3$, $S 1+S 2$ and $S 2$, respectively; simulation results are shown to verify the validity of theoretical work.

The effect of varying the top-loading, feeding structure and the ground-trace structure on the antenna performance has been studied. The configuration of varied antenna structure is shown in Figure 4(a), and the measured VSWR plot of the corresponding structure is shown in Figure 4(b). From Figure 4(b), it is obviously that the tuning of the $2450 \mathrm{MHz}$ band was acquired by adjusting the size of toploading to produce the required frequency response characteristic. The top-loading width increase will lead to an increase of impedance bandwidth and a decrease resonant frequency in the $2450 \mathrm{MHz}$ band, as shown in Figure 4(b). In addition, to let the co-planar waveguide feeding structure to be an asymmetric structure, it was observed that the resonant frequency and impedance bandwidth will increase in $2450 \mathrm{MHz}$ and $5500 \mathrm{MHz}$ bands and nevertheless, the effect in $700 \mathrm{MHz}$ band is very small. Furthermore, when the printed ground-trace was curled a meander-structure and spiral-structure, the operating bandwidth will increase. The ground-trace length (S3) and configuration could also affect the resonant frequency and operating bandwidth of the $700 \mathrm{MHz}$ band. The quantitative comparisons of the effects of varying antenna structure on the antenna's resonant frequency and impedance bandwidth were studied experimentally, as shown in Table 2 (the configuration of 

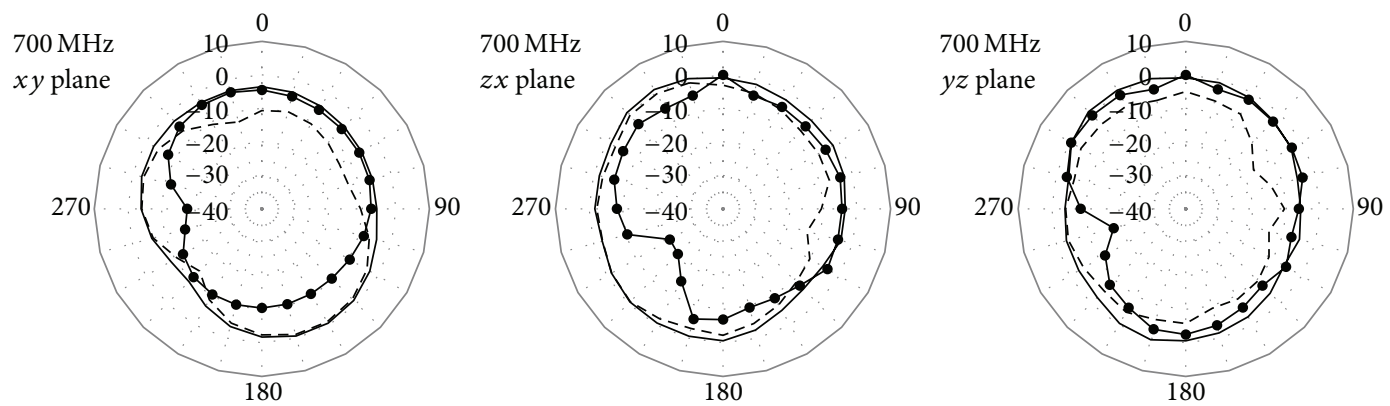

(a)
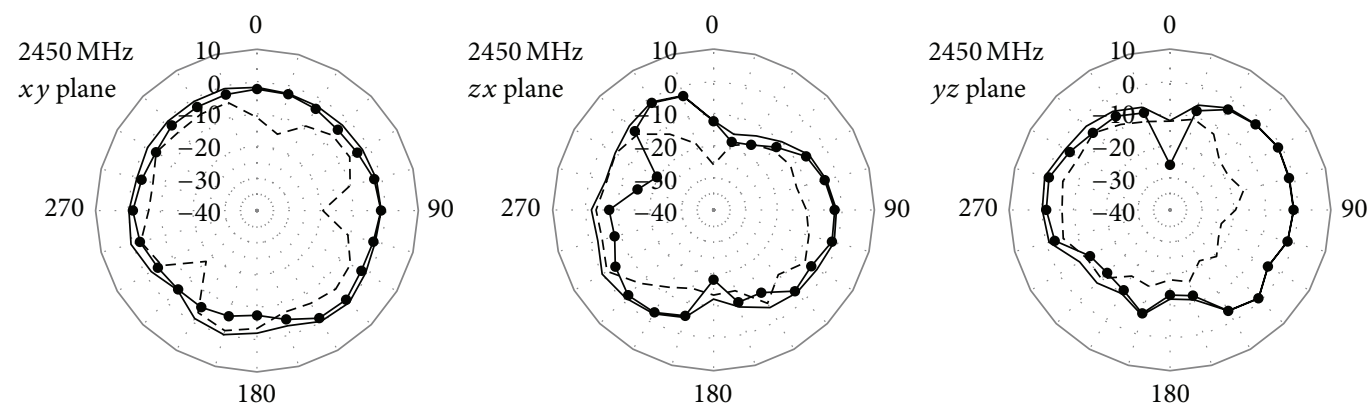

(b)
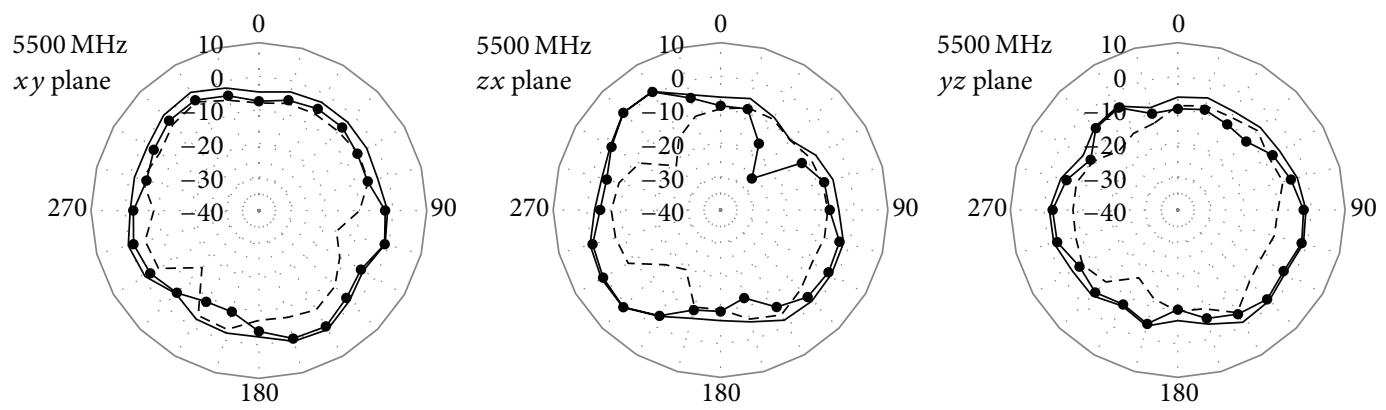

(c)

FIGURE 5: Measured radiation patterns for the proposed antenna. “- Total”, “•-• co-pol., “- - - cross-pol.” (a) 700 MHz. (b) 2450 MHz. (c) $5500 \mathrm{MHz}$.

varying antenna structure with $57.5 \mathrm{~mm}$ in length, $0.4 \mathrm{~mm}$ in thickness, and $5 \mathrm{~mm}$ in width, VSWR $\leq 2.5$ ). The impedance matching was also achieved by optimizing the steppedfeeding trace and open-stub. The measured radiation patterns for free space at $700 \mathrm{MHz}, 2450 \mathrm{MHz}$, and $5500 \mathrm{MHz}$ in the $x y$-plane, $y z$-plane, and $z x$-plane are shown in Figure 5, respectively. Table 3 shows the measured antenna gains and 3D pattern efficiency within the operating bands of the proposed antenna. Stable radiation patterns are observed. The total 3D pattern efficiency is defined as (gain/directivity) $\times$ $100 \%$, which was done by using pattern integration employing the ETS-Lindgren anechoic chamber. Acceptable radiation characteristic for the practical applications is obtained for the proposed antenna. The omnidirectional feature of the proposed antenna can also be observed from the $x y$-plane, where the gain variation between maximum and minimum levels is less than $3 \mathrm{~dB}$. The overall signal trace length is about one wavelength long and there are normally four lobes at the $5500 \mathrm{MHz}$ band, but, due to the ground trace is also acts as a sleeve balun, a close to complete radiation shape (there are a few variations in the radiation pattern-shapes) was obtained.

\section{Conclusion}

In this paper, a dual-band wideband printed asymmetric dipole antenna suitable for WLAN and LTE applications has been proposed. The antenna is characterized by reduced dimensions and suitable impedance matching over the presented operating band. The performances of the synthesized antenna have been numerically and experimentally verified. The proposed antenna can be easily fabricated and modified to various AP and router as a compact external antenna.

\section{Acknowledgments}

This work was sponsored by the National Science Council, under the Contract 101-2221-E-228-004-MY2 and Wieson Corp. Tech. (http://www.wieson.com), Taiwan, under the 
Contract JW101-F-411-148. The authors also appreciate the reviewer's comments to improve the quality of this paper.

\section{References}

[1] J. D. Kraus and R. J. Marhefka, Antennas, McGraw-Hill, New York, NY, USA, 2002.

[2] L. Lizzi and A. Massa, "Dual-band printed fractal monopole antenna for LTE applications," IEEE Antennas and Wireless Propagation Letters, vol. 10, pp. 760-763, 2011.

[3] J. Ma, Y. Z. Yin, J. L. Guo, and Y. H. Huang, "Miniature printed octaband monopole antenna for mobile phones," IEEE Antennas and Wireless Propagation Letters, vol. 9, pp. 1033-1036, 2010.

[4] K. Chung, S. Hong, and J. Choi, "Ultrawide-band printed monopole antenna with band-notch filter," IET Microwaves, Antennas and Propagation, vol. 1, no. 2, pp. 518-522, 2007.

[5] T.-G. Ma and S.-K. Jeng, "Planar miniature tapered-slot-fed annular slot antennas for ultrawide-band radios," IEEE Transactions on Antennas and Propagation, vol. 53, no. 3, pp. 1194-1202, 2005.

[6] A. Cabedo, J. Anguera, C. Picher, M. Ribó, and C. Puente, "Multiband handset antenna combining a PIFA, slots, and ground plane modes," IEEE Transactions on Antennas and Propagation, vol. 57, no. 9, pp. 2526-2533, 2009.

[7] I.-F. Chen and C.-M. Peng, "Printed broadband monopole antenna for WLAN/WiMAX applications," IEEE Antennas and Wireless Propagation Letters, vol. 8, pp. 472-474, 2009. 

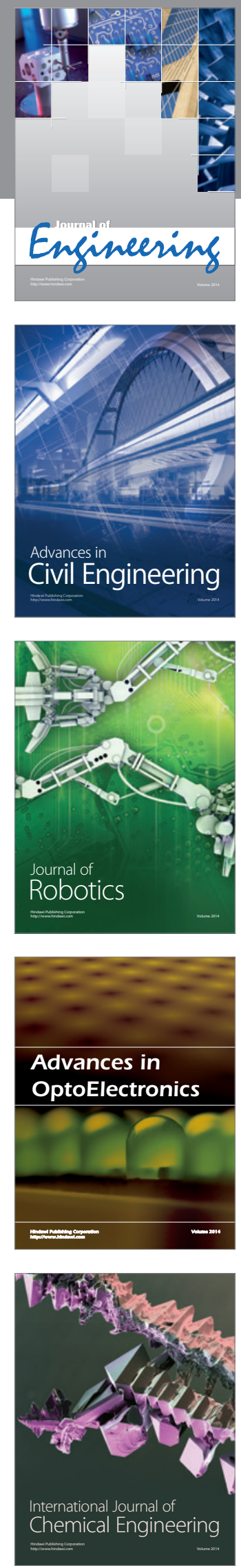

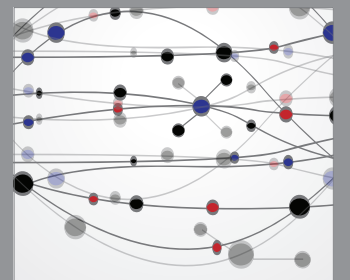

The Scientific World Journal
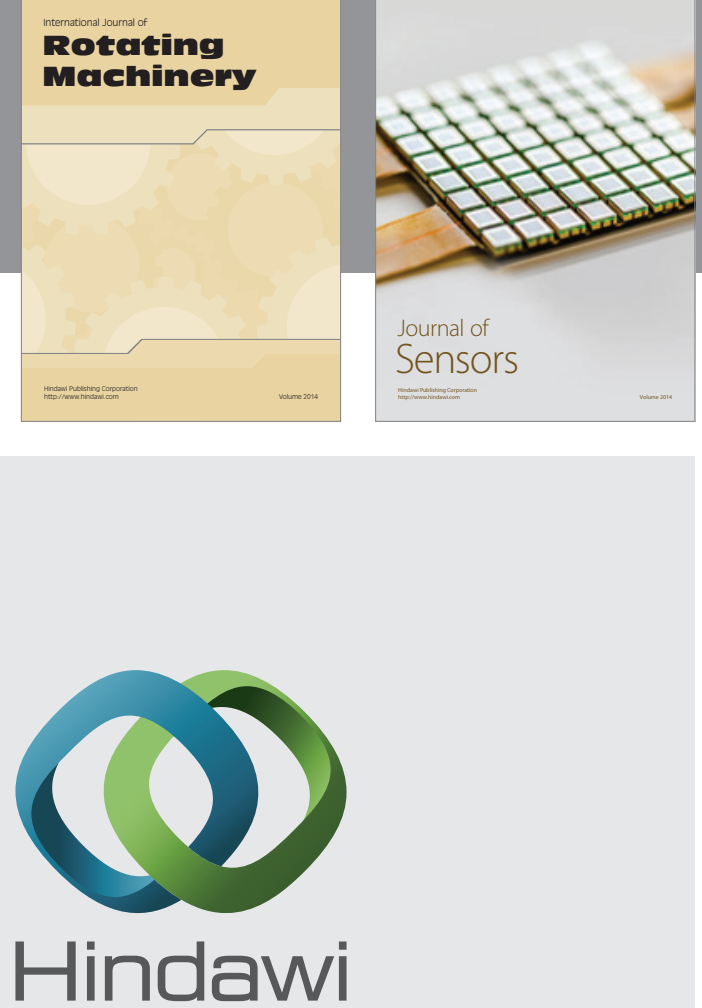

Submit your manuscripts at http://www.hindawi.com
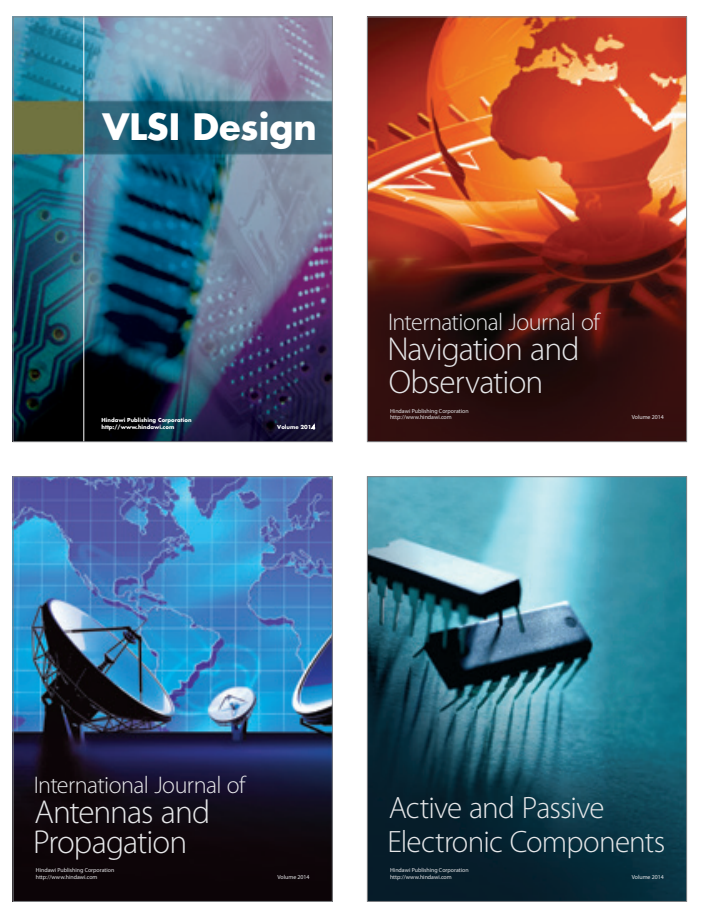
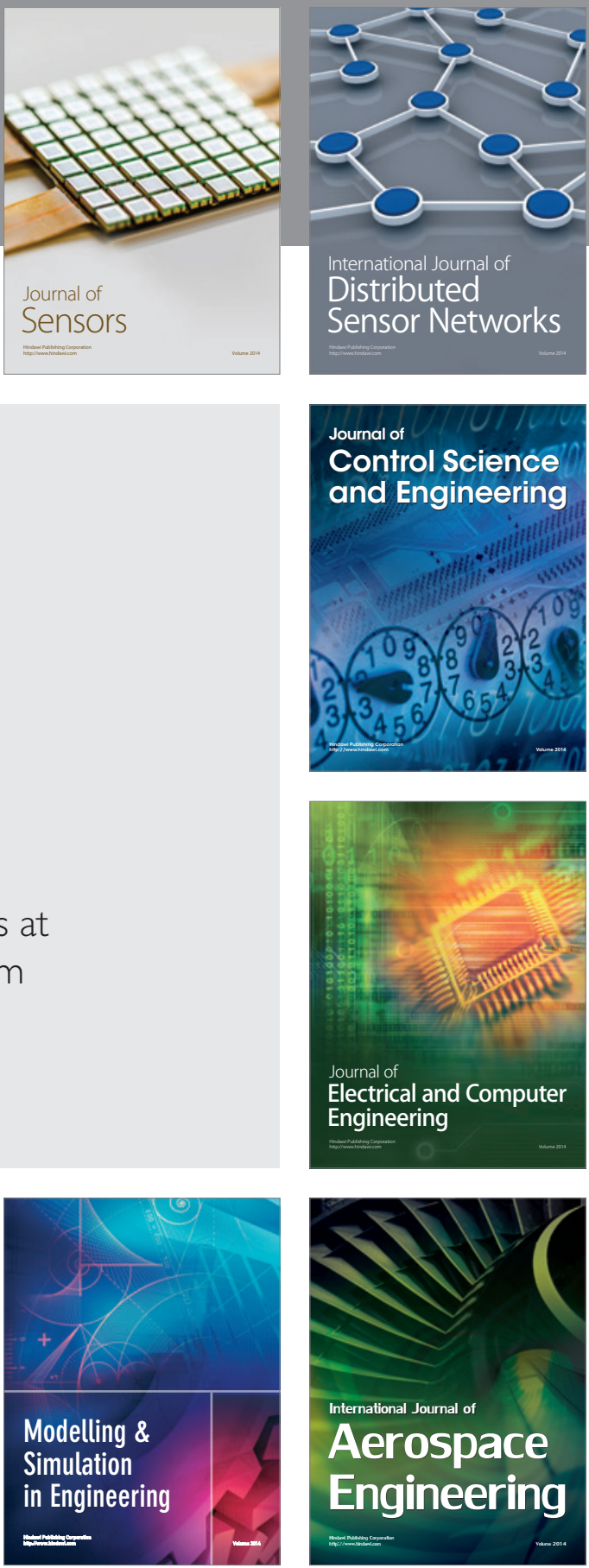

Journal of

Control Science

and Engineering
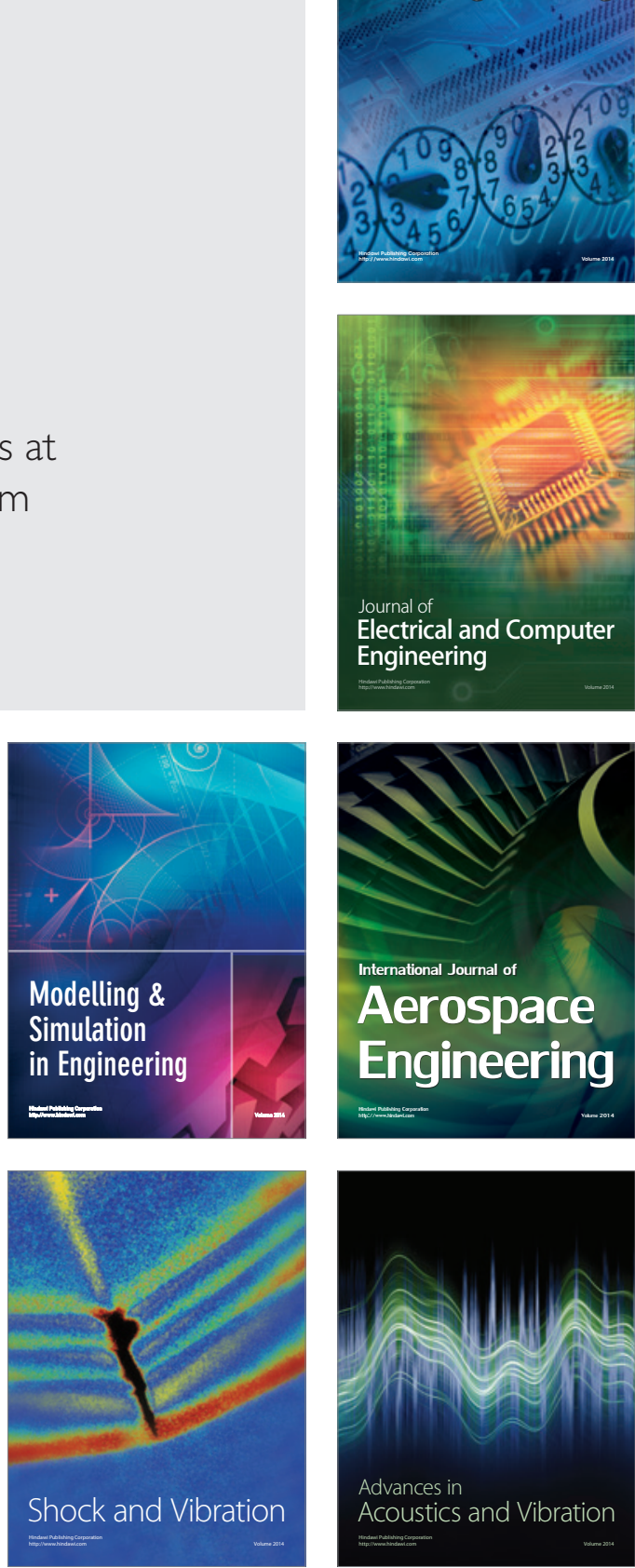